\title{
Applications of functional data analysis: A systematic review
}

Shahid Ullah ${ }^{* *}$ and Caroline F Finch ${ }^{2}$

\begin{abstract}
Background: Functional data analysis (FDA) is increasingly being used to better analyze, model and predict time series data. Key aspects of FDA include the choice of smoothing technique, data reduction, adjustment for clustering, functional linear modeling and forecasting methods.

Methods: A systematic review using 11 electronic databases was conducted to identify FDA application studies published in the peer-review literature during 1995-2010. Papers reporting methodological considerations only were excluded, as were non-English articles.

Results: In total, 84 FDA application articles were identified; $75.0 \%$ of the reviewed articles have been published since 2005. Application of FDA has appeared in a large number of publications across various fields of sciences; the majority is related to biomedicine applications (21.4\%). Overall, 72 studies (85.7\%) provided information about the type of smoothing techniques used, with B-spline smoothing (29.8\%) being the most popular. Functional principal component analysis (FPCA) for extracting information from functional data was reported in 51 (60.7\%) studies. One-quarter (25.0\%) of the published studies used functional linear models to describe relationships between explanatory and outcome variables and only $8.3 \%$ used FDA for forecasting time series data.

Conclusions: Despite its clear benefits for analyzing time series data, full appreciation of the key features and value of FDA have been limited to date, though the applications show its relevance to many public health and biomedical problems. Wider application of FDA to all studies involving correlated measurements should allow better modeling of, and predictions from, such data in the future especially as FDA makes no a priori age and time effects assumptions.
\end{abstract}

Keywords: Functional data analysis, Smoothing, Functional principal component analysis, Clustering, Functional linear model, Forecasting, Time series data

\section{Background}

Recent increased interest in the application of statistical modeling to medicine, biomedicine, public health, biology, biomechanics and environmental science has largely been driven by the need for good data to inform government policy and planning processes for health service delivery and disease prevention. Importantly, such models will only be useful in the long term if they are accurate, based on good quality data, and generated through application of robust appropriate statistical methods. Functional data analysis (FDA) is one such approach towards modeling time series data that has started to receive attention in the

\footnotetext{
* Correspondence: shahid.ullah@flinders.edu.au

${ }^{1}$ Flinders Centre for Epidemiology and Biostatistics, School of Medicine, Faculty of Health Sciences, Flinders University, Adelaide, SA 5001, Australia Full list of author information is available at the end of the article
}

literature, particularly in terms of its public health and biomedical applications.

Commonly, time series data are treated as multivariate data because they are given as a finite discrete time series. This usual multivariate approach completely ignores important information about the smooth functional behavior of the generating process that underpins the data [1]. It also suffers from issues associated with highly correlated measurements within each functional object. The basic idea behind FDA is to express discrete observations arising from time series in the form of a function (to create functional data) that represents the entire measured function as a single observation, and then to draw modeling and/or prediction information from a collection of functional data by applying statistical concepts from multivariate data analysis. In doing so, it has the advantage of generating
C Biomed Central

(c) 2013 Ullah and Finch; licensee BioMed Central Ltd. This is an Open Access article distributed under the terms of the Creative Commons Attribution License (http://creativecommons.org/licenses/by/2.0), which permits unrestricted use, distribution, and reproduction in any medium, provided the original work is properly cited. 
models that can be described by continuous smooth dynamics, which then allow for accurate estimates of parameters for use in the analysis phase, effective data noise reduction through curve smoothing, and applicability to data with irregular time sampling schedules. Ramsay $[2,3]$ presents a strong argument for FDA.

Ramsay and Dalzell [4] present several practical reasons for considering functional data:

1) smoothing and interpolation procedures can yield functional representations of a finite set of observations;

2) it is more natural to think through modeling problems in a functional form; and

3) the objectives of an analysis can be functional in nature, as would be the case if finite data were used to estimate an entire function, its derivatives, or the values of other functionals.

Müller has recently described important characteristics of FDA [5]. The FDA approach is highly flexible in the sense that the timing intervals for data observations do not have to be equally spaced for all cases and can vary across cases. Importantly, FDA methods are not necessarily based on the assumption that the values observed at different times for a single subject are independent. Although functional data themselves are not new, a new conceptualization of them has become necessary because of the increasing sophistication of available data collections [4]. Data collection technology has evolved over recent decades, allowing more dense sampling of observations over time, space, and other continuum measures. Such data are usually interpreted as reflecting the influence of certain smooth functions that are assumed to underlie and to generate the observations. Although classical multivariate statistical techniques are often applied to such data, they do not take advantage of additional information that could be implied by the smoothness of underlying functions. In particular, FDA methods can often extract additional information contained in the function and its derivatives [6,7] that is not normally available from application of traditional statistical methods [1]. Because the FDA approach essentially treats the whole curve as a single entity, there is also no concern about correlations between repeated measurements. This represents a change in philosophy towards the handling of time series and correlated data [8].

There are a number of good illustrations of applications of FDA; for example, Ramsay and Silverman $[9,10]$ using curves as data, Locantore et al. [11] with images as data, and Yushkevich and Pizer [12] where the data points are shape representations of body parts. Application of FDA has also been published across various scientific fields including analysis of child size evolution
[9], climatic variation [4,13], handwriting in Chinese [14], acidification processes [15], land usage prediction based on satellite images [16], medical research [17-19], behavioral sciences [20], term-structured yield curves [21], and spectrometry data [22]. Most recently, Ullah and Finch [23] found FDA to be an effective exploratory and modeling technique for highlighting trends and variations in the shape of the age-falls injury incidence relationship over time.

In contrast to most other methods commonly used to model trends in time series data, a key strength of the FDA approach is that it makes no parametric assumptions about age or time effects. The FDA methods for modeling and forecasting data across a range of health and demographic issues also have significant advantages for better understanding trends, risk factor relationships, and the effectiveness of preventive measures [24,25]. In the book Functional Data Analysis, Ramsay and Silverman [9] give an accessible overview of the foundations and applications of FDA. In an earlier book entitled Applied Functional Data Analysis, the same authors [10] provide many examples that share the property of being functional forms of a continuous variable, most often age or time. In 2004, Statistica Sinica published a special issue that included two relevant review articles that dealt exclusively with the close connection between longitudinal data and functional data [26,27]. In his PhD thesis, Ullah [28] described the significance and application of FDA in demographic data settings. Software developed for MATLAB, S-PLUS and R by Ramsay and Silverman specifically to support FDA is available from <http://www.psych.mcgill.ca/misc/fda/>.

Because the application of FDA is still relatively novel, especially to public health and biomedical data, this paper reviews applications of the approach to date with the aim of encouraging researchers to adopt FDA in future studies. This paper begins with a systematic review of the focus and application features of published peerreviewed FDA studies. In doing so, it provides a summary of the extent to which FDA has been applied in different fields, including an overview of the nature of the time series variables/data used. For each of the identified studies, this paper also describes the features of FDA that were used, including the:

(1) representation of data via principal components analysis, which plays a key role in defining smoothness and continuity conditions of the resulting data;

(2) classification of data, which produces different functional groups (or clusters) for gaining more sophisticated knowledge of different pathways and/ or functions for large scale data;

(3) functional linear models used for testing the effects on outcomes in functional form; and 
(4)forecasting via stochastic methods, to measure the forecast uncertainty through the estimation of a prediction interval.

\section{Methods}

This review was conducted according to the Preferred Reporting Items for Systematic Reviews and MetaAnalyses (PRISMA) Statement [29]. We conducted a systematic search of 11 electronic databases to identify peerreviewed FDA application studies published between January 1995 and December 2010. The databases used were Academic Search Premier, ScienceDirect, SpringerLink, Cambridge Journals, MEDGE (Informit), Oxford Journals, PubMed, Sage Journals Online, Web of Science, Wiley Interscience Journals, and MEDLINE. We used the phrase functional data analysis to identify relevant articles, and considered only English language articles published in peer-reviewed journals. In addition to the electronic database search, the search strategy included secondary searching of the reference lists of identified articles.

\section{Inclusion and exclusion criteria}

Studies were eligible for inclusion if they were original research articles in peer-reviewed journals reporting an application of FDA. We excluded studies of statistical methodology development without application, and abstracts, letters, and conference papers.

\section{Identification of studies}

The first author, with the assistance of two research assistants, sourced and screened all identified articles. This included viewing titles and reading abstracts. We obtained full text versions of potentially eligible articles, assessed them against the exclusion/inclusion criteria, and removed obvious exclusions.

In the first review phase, 334 articles were identified. Figure 1 summarizes the numbers of studies identified and the reasons for exclusion at each stage. Searching the titles and abstracts of identified studies excluded 160 (47.9\%) articles that were not directly relevant to statistical FDA applications. These included reports of functional magnetic resonance imaging (fMRI) to assess patterns of brain activation in patients suffering from chronic traumatic brain injury [30], functional performance in participants with functional ankle instability [31], and the relationship between neurocognitive function and noncontact anterior cruciate ligament injuries [32].

In the second phase, we conducted a complete detailed review of the remaining 174 retrieved articles to ensure they fully met the inclusion and exclusion criteria. A

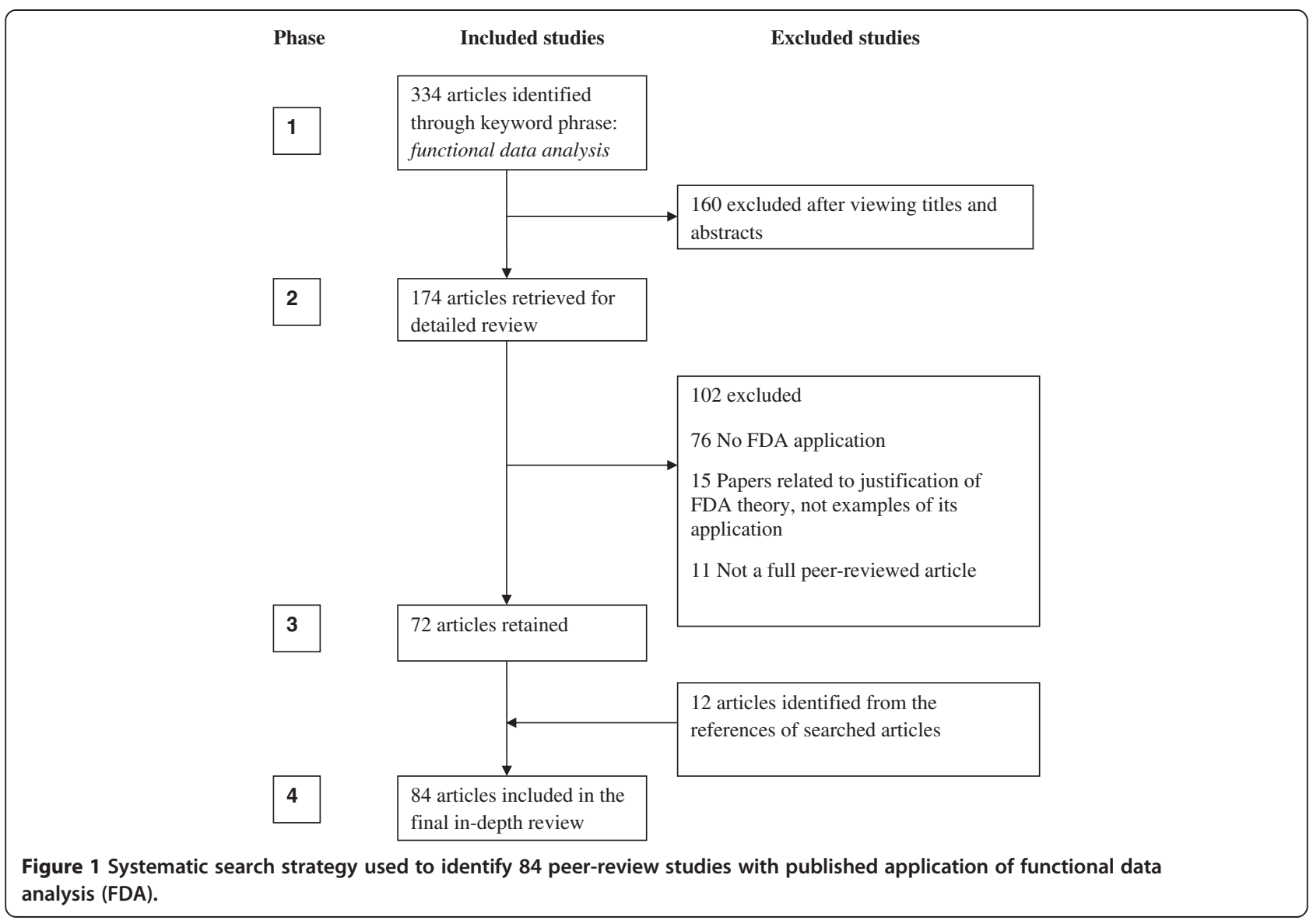


further 102 articles were excluded at this stage, leaving 72 peer reviewed articles for the third phase. Studies excluded at this stage were mainly those that justified FDA theory rather than presenting examples of its application [8,33-35]. A further 12 articles were found in the manual search of reference lists of the 72 retained articles.

We retained a final set of 84 articles for detailed review. The lead author reviewed each paper in terms of key FDA criteria, as outlined below, and assessed its field of application and the specific FDA methods applied. Figure 1 uses the PRISMA [29] flowchart to summarize all stages of the paper selection process.

\section{Results}

\section{Overview of the published FDA studies}

Table 1 summarizes the final set of reviewed papers, and shows fields of application, outcome of interest, and use of the following important FDA features:

- smoothing technique;

- use of functional principal component analysis (FPCA);

- type of clustering adjustment;

- functional linear modeling (FLM) approach adopted to relate explanatory and outcome variables; and

- type of forecasting (if any).

The earliest identified application of FDA was in 1995 and $75 \%$ of the reviewed articles were published since 2005. This reflects increasing recognition of the important features of functional data and awareness of the development of new statistical approaches and software for handling them.

While diverse fields were covered in the published studies, almost $21 \%$ of the studies related specifically to biomedical science (18 identified papers), followed by biomechanics applications (11 papers). Other fields of application were medicine (10), linguistics (6), biology (4), ecology (4), psychology (4), meteorology (4), environmental studies (4), demography (3), finance (3), neurology (2), economics (2), engineering (2), agriculture (1), physiology (1), information technology (1), education (1), chemistry (1), geophysics (1), and behavioral science (1). In relation to specific health issues, the most common topics were analyses of kinematics gait data (9 papers), magnetic resonance imaging (6 papers), and yeast cell cycle temporal gene expression profiles (6 papers).

\section{Important features of the published FDA studies}

Table 1 summarizes the published studies in terms of their use of the following key features of FDA: the reported smoothing technique, FPCA, clustering, the adopted forms of the FLM and forecasting. The importance of each of these features is explained below and an overview given of how they were handled in the published studies.

\section{Smoothing techniques}

Smoothing is the first step in any FDA, and its purpose is to convert raw discrete data points into a smoothly varying function. This emphasizes patterns in the data by minimizing short-term deviations due to observational errors, such as measurement errors or inherent system noise. When reporting FDA studies, it is important to state the smoothing approach used because observational errors always exist in longitudinal data.

Table 1 summarizes the various smoothing techniques used to estimate functions from the discrete observations reported in the reviewed literature. Overall, all except twelve of the studies (i.e. $85.7 \%$ of the reviewed studies) provided information about the type of smoothing technique used. Although some authors believe that FDA can be considered as a smoothed version of multivariate data analysis, smoothing techniques should still be used to reduce some of the inherent randomness in the observed data $[1,25,113]$.

Overall, B-spline smoothing was the most popular smoothing technique used (25 papers), presumably because of its simplicity and flexibility for tackling a wide range of nonparametric and semiparametric modeling situations. A common approach towards B-spline smoothing is to construct a large number of knots (as the smoothing parameter) to reduce the effective degrees of freedom and increase smoothness in the overall function estimate $[114,115]$. Other smoothing techniques adopted in the published studies included use of Fourier smoothing (8 papers), regression splines (6), kernel smoothing (7), polynomial splines (5), cubic splines (3), smoothing splines (3), wavelet bases (3), roughness penalties (2), local polynomials (2), local quadratics (1), local weighted regression (1), P-splines (1) and log-splines (1).

Ramsay and Silverman [9] emphasize that the choice of smoothing technique is dependent upon the underlying behavior of the data being analyzed. Ideally, the smoother should reflect or have features that match those of the data. For example, Fourier smoothers are traditionally used when the data are cyclical or periodic. Environmental diurnal ozone and $\mathrm{NO}_{\mathrm{x}}$ cycles $[71,116]$, trends in ecologically meaningful water quality variates in ecology [81], cash flows in finance [92] and fetal heart rate monitoring in medicine $[18,19]$ are examples of the application of Fourier smoothers. Splines (regression splines, polynomial splines, B-spline) are typically chosen to represent noncyclical nonperiodic data $[25,51,84]$, and wavelet bases are chosen to represent data displaying discontinuities and/or rapid changes in behavior $[117,118]$. Most recently, Ullah and Finch [23] used constrained penalized 
Table 1 Areas of application and the functional data analysis (FDA) features used in the 84 peer-review papers reporting application of FDA

\begin{tabular}{|c|c|c|c|c|c|c|c|c|}
\hline \multirow[t]{2}{*}{ Year } & \multirow{2}{*}{$\begin{array}{l}\text { Field of } \\
\text { study }\end{array}$} & \multirow[t]{2}{*}{ Outcome of interest } & \multicolumn{5}{|c|}{ FDA features } & \multirow[t]{2}{*}{ Reference } \\
\hline & & & Smoothing & $\begin{array}{l}\text { Data } \\
\text { reduction }\end{array}$ & Clustering & FLM & Forecasting & \\
\hline \multirow[t]{12}{*}{2010} & Biomechanics & Walking velocity on force platform & - & - & - & FRM & - & {$[36$} \\
\hline & Biomechanics & Kinematic gait data & Polynomial spline & FPCA & - & - & - & {$[3$} \\
\hline & Biomedicine & Diffusion tensor imaging fiber images & Kernel & - & - & FRM & - & {$[3$} \\
\hline & Biomedicine & Gene expression microarray data & Local polynomial & FPCA & FEM & - & - & {$[3$} \\
\hline & Biomedicine & Spinal cord dorsal horn neurons & $\begin{array}{l}\text { Locally weighted } \\
\text { regression (LOESS) }\end{array}$ & - & K-Means & - & - & \\
\hline & Demography & Age-specific mortality rates & Kernel & FPCA & - & - & - & {$[4$} \\
\hline & Environment & Gas emissions & Kernel & - & - & - & - & {[} \\
\hline & Geophysics & Magnetometer & Kernel & FPCA & - & FRM & - & {$[4$} \\
\hline & Medicine & Human growth & - & FPCA & - & - & - & [4 \\
\hline & Medicine & Age-specific breast cancer mortality rates & $\begin{array}{l}\text { Penalized } \\
\text { regression spline }\end{array}$ & FPCA & - & - & $\begin{array}{l}\text { State space } \\
\text { model }\end{array}$ & {$[4$} \\
\hline & Medicine & Age-specific fall injury incidence rates & $\begin{array}{l}\text { Penalized } \\
\text { regression spline }\end{array}$ & FPCA & - & - & $\begin{array}{l}\text { State space } \\
\text { model }\end{array}$ & \\
\hline & Medicine & Human vision & Wavelet & - & - & FANOVA & - & \\
\hline \multirow[t]{8}{*}{2009} & Biology & Temporal fertility trajectories of medfly & - & FPCA & - & FMANOVA & - & {$[4$} \\
\hline & Biomechanics & Kinematic gait data & - & - & - & FRM & - & {$[4$} \\
\hline & Biomedicine & $\begin{array}{l}\text { 3-Tesla magnetic resonance imaging } \\
\text { data }\end{array}$ & - & FPCA & - & - & - & \\
\hline & Biomedicine & $\begin{array}{l}\text { Denaturing gradient gel electrophoresis } \\
\text { data }\end{array}$ & B-spline & FPCA & $\mathrm{HCA}$ & - & - & {$[5$} \\
\hline & Biomedicine & $\begin{array}{l}\text { microRNA transfection time-series } \\
\text { microarray expression images }\end{array}$ & B-spline & FPCA & - & - & - & \\
\hline & Biomedicine & $\begin{array}{l}\text { Paediatric diffusion tensor imaging } \\
\text { images }\end{array}$ & B-spline & FPCA & - & - & - & {$[5$} \\
\hline & Biomedicine & $\begin{array}{l}\text { Positron emission tomography time } \\
\text { course data }\end{array}$ & Local polynomial & FPCA & - & - & - & \\
\hline & Meteorology & Clickstream web data (Hurricane Katrina) & B-spline & - & - & FANOVA & - & {$[5$} \\
\hline \multirow[t]{12}{*}{2008} & Biomechanics & $\begin{array}{l}\text { Ankle dorsiflexion, knee flexion, Achilles } \\
\text { tendon, calcaneal and leg } \\
\text { abduction angles }\end{array}$ & Roughness penalty & FPCA & - & - & - & {$[5$} \\
\hline & Biomedicine & Colon carcinogenesis experiments & Regression splines & FPCA & - & - & - & {$[5$} \\
\hline & Biomedicine & Diffusion tensor imaging fiber images & B-spline & FPCA & - & - & - & {$[5$} \\
\hline & Biomedicine & $\begin{array}{l}\text { Temporal gene expression profiles for the } \\
\text { Drosophila life cycle }\end{array}$ & Smoothing spline & FPCA & - & FRM & - & \\
\hline & Biomedicine & Time-course gene expression data & B-spline & - & SVM & - & - & {$[5$} \\
\hline & Biomedicine & Time-course gene expression data & B-spline & FPCA & $\begin{array}{l}\text { LDA, QDA } \\
\text { KNN, SVM }\end{array}$ & - & - & \\
\hline & Demography & Mortality, fertility and migration rates & $\begin{array}{l}\text { Weighted penalized } \\
\text { regression spline }\end{array}$ & FPCA & - & - & $\begin{array}{l}\text { State space } \\
\text { model }\end{array}$ & \\
\hline & Ecology & Plankton monitoring data & Roughness penalty & FPCA & - & - & - & {$[6$} \\
\hline & Environment & $\begin{array}{l}\text { Diurnal ozone and NOx cycles for } \\
\text { transportation emission control }\end{array}$ & Fourier & FPCA & $\mathrm{HCA}$ & - & - & [62 \\
\hline & Finance & Cash flow and transactions & Wavelet & FPCA & - & - & FAR & {$[6$} \\
\hline & Finance & Price formation and online auctions & Polynomial spline & - & - & FRM & - & {$[6$} \\
\hline & Linguistics & $\begin{array}{l}\text { Speech production variability in fricatives } \\
\text { of children and adults }\end{array}$ & B-spline & FPCA & - & - & - & \\
\hline
\end{tabular}


Table 1 Areas of application and the functional data analysis (FDA) features used in the 84 peer-review papers reporting application of FDA (Continued)

\begin{tabular}{|c|c|c|c|c|c|c|c|c|}
\hline & Meteorology & Plasma biomarkers & Kernel & - & - & FRM & - & [66] \\
\hline & Psychology & Emotional responses of musical listeners & Cubic B-spline & - & - & FANOVA & - & [67] \\
\hline \multirow[t]{10}{*}{2007} & Biology & $\begin{array}{l}\text { Time-course gene expression yeast } \\
\text { cell cycle }\end{array}$ & B-spline & FPCA & MBC & - & - & [68] \\
\hline & Biomedicine & MRI images & B-spline & - & - & - & - & [69] \\
\hline & Demography & Mortality and fertility rate & $\begin{array}{l}\text { Penalized } \\
\text { regression spline }\end{array}$ & FPCA & - & - & $\begin{array}{l}\text { State space } \\
\text { model }\end{array}$ & {$[25]$} \\
\hline & Engineering & Radar waveforms & Kernel & - & $\mathrm{HCA}$ & - & - & [70] \\
\hline & Environment & $\begin{array}{l}\text { Diurnal ozone/NOx cycles and } \\
\text { transportation emissions }\end{array}$ & Fourier & - & - & FANOVA & - & [71] \\
\hline & Environment & Stratospheric ozone levels & Cubic spline & FPCA & - & - & - & [72] \\
\hline & Medicine & Age-specific breast cancer mortality rates & $\begin{array}{l}\text { Weighted local } \\
\text { quadratic }\end{array}$ & FPCA & - & - & $\begin{array}{l}\text { State space } \\
\text { model }\end{array}$ & [24] \\
\hline & Medicine & $\begin{array}{l}\text { Women urinary hormone profiles at } \\
\text { midlife }\end{array}$ & Cubic spline & FPCA & - & - & - & [73] \\
\hline & Medicine & Haemoglobin levels in renal anaemia & B-spline & - & - & - & - & [74] \\
\hline & Neurology & $\begin{array}{l}\text { Joint coordination data in motor } \\
\text { development }\end{array}$ & B-spline & FPCA & - & - & - & {$[75]$} \\
\hline \multirow[t]{10}{*}{2006} & Biology & $\begin{array}{l}\text { Time-course gene expression yeast } \\
\text { cell cycle }\end{array}$ & B-spline & FPCA & FLR & - & - & [76] \\
\hline & Behavioural & Male medfly calling behaviour & - & FPCA & - & - & - & [77] \\
\hline & Biomechanics & Kinematic gait data (knee flexion angle) & Cubic B-spline & FPCA & LDA & - & - & [78] \\
\hline & Biomechanics & Knee joint kinematics in the vertical jump & B-spline & FPCA & - & - & - & [79] \\
\hline & Biomechanics & $\begin{array}{l}\text { Kinematic gait data } \\
\text { (sit to stand movements) }\end{array}$ & B-spline & - & - & - & - & {$[80]$} \\
\hline & Ecology & $\begin{array}{l}\text { Water quality trend data } \\
\text { (nutrient and sediment) }\end{array}$ & Fourier & FPCA & $\mathrm{HCA}$ & FRM & - & [81] \\
\hline & IT & Software complexity measure & Smoothing spline & - & - & - & - & [82] \\
\hline & Linguistics & Tongue tip velocity & B-spline & - & - & - & - & [83] \\
\hline & Physiology & $\begin{array}{l}\text { Blood lactate for running speed on a } \\
\text { treadmill }\end{array}$ & Polynomial spline & FPCA & - & - & - & {$[84]$} \\
\hline & Psychology & Tension judgement in music & B-spline & - & - & - & - & {$[85]$} \\
\hline \multirow[t]{9}{*}{2005} & Biology & Protein expression profiles & P-spline & FPCA & $\mathrm{HCA}$ & - & - & [86] \\
\hline & Biomechanics & Joint angles describing the limb motion & Regression spline & FPCA & - & - & - & [87] \\
\hline & Biomedicine & $\begin{array}{l}\text { Functional magnetic resonance imaging } \\
\text { data from 1.5-Tesla Magnetom vision }\end{array}$ & B-spline & FPCA & - & - & - & [88] \\
\hline & Biomedicine & $\begin{array}{l}\text { Functional magnetic resonance imaging } \\
\text { data from } 3.0 \text { T Allegra system- }\end{array}$ & B-spline & FPCA & - & - & - & {$[89]$} \\
\hline & Ecology & Smith McIntyre grab species & - & FPCA & $\mathrm{HCA}$ & - & - & [90] \\
\hline & Education & $\begin{array}{l}\text { Trends in Mathematics and Science } \\
\text { Achievement (TIMSS) score }\end{array}$ & $\begin{array}{l}\text { Nonparametric } \\
\text { spline }\end{array}$ & FPCA & CART,KNN & - & - & [91] \\
\hline & Finance & $\begin{array}{l}\text { Cash flows in point of sale and } \\
\text { ATM networks }\end{array}$ & Fourier & - & - & FANOVA & - & [92] \\
\hline & Linguistics & Speech movement records & Wavelets & - & - & - & - & [93] \\
\hline & Psychology & Tension judgement in music & B-spline & - & - & - & - & [94] \\
\hline \multirow[t]{3}{*}{2004} & Chemistry & Molecular weight distributions & B-spline & - & - & FRM & - & [95] \\
\hline & Medicine & Esophageal bolus flow & - & - & - & - & - & [96] \\
\hline & Meteorology & Biomarkers & Cubic spline & FPCA & - & - & - & [97] \\
\hline
\end{tabular}


Table 1 Areas of application and the functional data analysis (FDA) features used in the 84 peer-review papers reporting application of FDA (Continued)

\begin{tabular}{|c|c|c|c|c|c|c|c|c|}
\hline & Neurology & $\begin{array}{l}\text { Automated atlas-based head } \\
\text { size normalization }\end{array}$ & - & - & - & - & - & [98] \\
\hline & Psychology & Musical emotions and tension & B-spline & - & - & - & - & [99] \\
\hline \multirow[t]{2}{*}{2003} & Biomechanics & $\begin{array}{l}\text { Digitized images of hand drawing curves } \\
\text { generated by subjects treated with } \\
\text { various facial preparation }\end{array}$ & Fourier & FPCA & - & FANOVA & - & [100] \\
\hline & Biomedicine & Longitudinal plasma folate data & $\begin{array}{l}\text { Weighted local } \\
\text { polynomial spline }\end{array}$ & FPCA & - & - & - & [101] \\
\hline \multirow[t]{5}{*}{2002} & Agriculture & $\begin{array}{l}\text { Lodging score for rice fields based on a } \\
\text { digital overhead image }\end{array}$ & Fourier & - & - & FRM & - & [102] \\
\hline & Biomedicine & Myocardial contractile function images & Cubic B-spline & FPCA & - & - & - & [103] \\
\hline & Economics & $\begin{array}{l}\text { Monthly nondurable goods production } \\
\text { index }\end{array}$ & B-spline & - & - & - & - & [104] \\
\hline & Medicine & Foetal heart rate data & Fourier & - & - & FRM & - & [18] \\
\hline & Medicine & Foetal heart rate data & Fourier & - & - & FLRM & - & [19] \\
\hline 2001 & Satellite & Radar electromagnetic signals & Kernel & FPCA & - & & - & [105] \\
\hline \multirow[t]{3}{*}{2000} & Biomechanics & Handwriting in Chinese & B-spline & FPCA & EDO & - & - & [14] \\
\hline & Linguistics & Harmonics-to-noise ratio of voice signals & B-spline & - & - & - & - & [106] \\
\hline & Meteorology & Annual cycle of sea surface temperatures & Polynomial spline & - & - & - & FAR & [107] \\
\hline 1999 & Linguistics & Harmonics-to-noise ratio of voice signals & - & - & - & - & - & [108] \\
\hline 1998 & Ecology & $\begin{array}{l}\text { Abundance of the gray-sided vole } \\
\text { Clethrionomys rufocanus }\end{array}$ & Log-spline & FPCA & - & - & - & [109] \\
\hline 1996 & Linguistics & Vocal tract lip motion during speech & Smoothing spline & FPCA & - & FANOVA & - & [110] \\
\hline 1995 & Biomechanics & $\begin{array}{l}\text { Records of the force exerted by pinching } \\
\text { a force meter with the tips of the thumb } \\
\text { and forefinger an opposite sides }\end{array}$ & - & FPCA & - & - & - & [111] \\
\hline & Economics & Income distribution & - & FPCA & - & - & - & [112] \\
\hline
\end{tabular}

FPCA - Functional principal component analysis; FEM - Functional embedding; HCA - Hierarchical cluster analysis; SVM - Support vector machine; LDA- Linear discriminant analysis; QDA - Quadratic discriminant analysis; KNN- K-nearest neighbours; MBC - Model based clustering; CART - Classification and regression tree; EDO - Estimated differential operators; FLM - Functional linear model; FRM - Functional linear regression model; FANOVA - Functional ANOVA; FMANOVA - Functional MANOVA; FFT - Functional F test; FLRM - Functional logistic regression model; FAR - Functional auto regressive model.

regression splines with a monotonic constraint to represent their smooth curves of falls incidence rates.

\section{Data reduction}

The FPCA is one of the most popular multivariate analysis techniques for extracting information from functional data $[119,120]$. This approach reduces the dimensions of a data set in which there are a large number of interrelated variables, while still holding as much of the total variation as possible. This reduction is obtained by transforming the data to a new set of variables, or principal components, that are uncorrelated and ordered so that the first few retain most of the variation present in all of the original variables.

The use of FPCA was reported in 51 (60.7\%) of the reviewed studies (Table 1). It has been successfully applied to real life problems such as modeling the curvature of the cornea in the human eye [11], in a set of density curves where the argument variable is log income [121], and fMRI scans of areas in the human brain [88]. Many different applications of principal component analysis to functional data have been developed, including a useful extension of FPCA that allows the estimation of harmonics from fragments of curves [122]. Although FPCA is an important feature of FDA, not all studies reported it because they did not undertake data reduction. For example, Roislin et al. [48] used a functional regression model to estimate the effects of gender, age, and walking speed on kinematic gait data; Park et al. [58] classified gene functions using a support vector machine (clustering) for time-course gene expression data; and Lucero [93] used only a B-spline to smooth the harmonics-to-noise ratio of voice signals. None of these applications required FPCA to reduce the data.

\section{Clustering}

While FPCA results in dimension reduction, FPCA vector scores can be used for clustering different functions/components using standard clustering methods. Clustering is one of the most frequently used techniques for partitioning a dataset into subgroups that contain instances that are 
similar to each other while being clearly dissimilar to those of other groups. In a functional context, clustering helps to identify representative curve patterns and individuals who are very likely to be involved in the same or similar processes. For example, in time-course microarray experiments, thousands of gene expression measures are taken over time [123] and an important problem is to discover functionally related genes that could then be the target for new gene regulatory networks or functional pathways. Clustering of data allows identification of groups of genes with similar expression patterns to identify such networks and pathways.

A number of clustering methods were reported in the reviewed literature (Table 1) and most of these were exploratory techniques for gene expression data. Overall, 15 studies (17.9\%) reported some form of clustering. Biologists and ecologists used clustering to classify genes $[68,76]$ and ecological components $[81,90]$ within their studies. The most commonly applied clustering algorithms were hierarchical in nature (7 papers). Hierarchical algorithms define a dendrogram (tree) relating similar objects in the same sub-trees. In each step, similar sub-trees (clusters) are merged to form a dendrogram that clearly shows the different distinct clusters. Other reported clustering methods were linear discriminant analysis (LDA) (2 papers), k-nearest neighbors (KNN) (3), support vector machine (SVM) approaches (2), model-based clustering (MBC) (1), quadratic discriminant analysis (QDA) (1) and estimated differential operators (EDO) (1).

The LDA and QDA are both classical clustering methods and commonly used in microarray analysis [124,125]. Application of LDA is based on finding linear combinations of gene expression levels called discriminants that maximize the ratio of between-group variation to within-group variation. The QDA approach is a generalization of the linear classifier, allowing covariance matrices to be heterogeneous, whereas LDA functions are based on the assumption that covariance matrices of each of the classes are equal. This assumption relaxation can prevent individuals from being placed into classes with larger variance on their covariance matrix diagonals. The KNN is a nonparametric classification method based on the distance between individuals $[126,127]$. For example, Song et al. [59] proposed KNN to classify time-course gene expression profiles based on information from the data patterns. The SVM approach [128] is an extremely powerful methodology for classification problems and has a wide range of applications. Recently, this method has received much attention in classification problems that arise with the analysis of microarray data $[58,59]$. The MBC method assumes that the data are generated by a multivariate normal mixture distribution with appropriate means and covariance matrix [129]. Song et al. [68] have applied this method of clustering time-course gene expression data.

\section{Functional linear models}

An interesting application of FDA involves the construction of functional models that describe the relation between an outcome variable and an explanatory variable. Such models are termed functional linear models (FLMs). The number of published applications involving functional data has been steadily growing. In functional linear models, the functions could be the outcome or the predictors or both.

Of the reviewed studies in Table 1, 21 (25.0\%) reported some form of FLM. The approach most favored by authors was a basic functional linear regression model (12 papers). When the outcome variable is in its functional form and the relationship is almost linear, the methodology is called functional linear regression model, or FRM. Functional ANOVA (FANOVA) was used in eight studies. Vines et al. [85] developed a functional F test (FFT) for linear models with functional outcomes in their psychological study for measuring tension judgment in music. They illustrated how to apply the FFT to longitudinal data where intrasubject repeated measures are viewed as discrete samples from an underlying curve with a continuous functional form. One study applied a functional logistic regression model (FLRM) to fetal heart rates [18] and another applied functional multivariate analysis of variance (FMANOVA) to temporal fertility trajectories of medfly populations [47].

\section{Forecasting framework}

The recent introduction of stochastic methods for forecasting functional data has significant advantages over the standard approaches for better understanding trends, risk factor relationships, and the effectiveness of preventive measures. A major advantage of these methods is that they can measure forecast uncertainty through the estimation of prediction intervals for future data. For this reason, the FDA forecasting approach has started to receive attention in both demographic and medical applications $[24,25,28,60]$. To date there has only been limited application of FDA to epidemiological studies relating to the prediction of incidence/prevalence rates, with only one recent study applying it to forecast the incidence of fall-related severe head injuries [23].

Overall, only seven of the reviewed studies (8.3\%) reported any FDA-derived forecasting. A state space model was the most common approach for forecasting functional data in these studies (5 papers). In the forecasting process, the authors estimated the coefficients from a time series, with one value representing each time point, and a state space model was used to model and forecast these time series coefficients [23-25,28,130].

\section{Discussion}

Modern data analysis has greatly benefited from the development of FDA methods and their application to time 
series data. Although used by statisticians for many years, FDA provides a relatively novel approach to modeling and prediction that is highly suitable for public health and biomedical applications. This paper has summarized papers describing FDA applications with a main emphasis on five popular features: smoothing, FPCA, clustering, FLM, and forecasting.

Overall, the published FDA application studies demonstrate the value of this approach for exploring complex multivariate functional relationships and its major strength of being able to model the functional form of time series data. Different approaches allow for FDA representations as smooth functions, and the published studies used a range of smoothing techniques for the estimation of discretely observed data. The FDA approach of initially smoothing the data and then using the smoothed observations for modeling and forecasting is a major methodological improvement over methods that simply fit linear/non-linear trends to observed data. These FDA approaches are very suitable for widespread public health and biomedical applications. Although some authors believe that FDA can be considered as a smoothed version of multivariate data analysis, recent work has shown the advantage of direct application of smoothing techniques to reduce some of the inherent randomness in the observed data $[1,25,113]$.

The theoretical and practical developments that have occurred over recent years mean that researchers can now successfully apply FPCA to many practical problems, with main attention given to the reduction of data dimensions to a finite level and identification of the most significant components of the data. High dimensional data significantly slow down conventional statistical algorithms and in some cases it is not feasible to use them in practice. This means that standard classification methods can suffer from difficulties when handling such data. Some studies need to compress their data to facilitate exploration of the most important features (e.g., characteristics of genes from entire time-course data). In such instances, dimension reduction should be applied to keep only the relevant information and for removing correlations. This will both speed up and improve the accuracy of subsequent analyses and modeling. The FPCA has proven to be a key technique for dimension reduction, reported in most of studies reviewed here. It can also be used to investigate the variability of data with respect to individual curve shapes [131].

One of the major application areas highlighted in this review is an apparent increasing interest in clustering and classification techniques, especially for time-course gene expression data. The clustering is useful for detecting patterns and clusters in high dimensional functional data. Functional clustering is used to search for natural groupings of data with similar characteristics. Unlike conventional clustering that requires measuring multivariate data at the same time points to calculate Euclidean 'distances' between observations, functional clustering can derive a broader class of distance measures even if the original measurements are not time-aligned among sampling units, as is common in public health applications. The reason for the popularity of functional clustering is that it can classify time series data into different classes without requiring $a$ priori knowledge of data.

A very interesting application of FDA involves the construction of linear models that describe the relation between an outcome variable and explanatory variables with functional nature. The FLMs have recently gained popularity and the related literature has been steadily growing with several studies using covariates to explain functional variables. Overall, FRM and FANOVA methods were the most prominent in the reviewed literature. Reasons for not using FLM techniques are unclear but might include a lack of knowledge about the value of building functional models for public health and biomedical data. However, the use of FLM is not always necessary and depends on the specific research questions.

Public health researchers now recognize the importance of understanding trends in high dimensional time series data. Policy makers, for example, need information about predicted trends to inform their decision-making about public health and economic investments to reduce the burden into the future [132]. It is critical that such predictions are robust and based on the best available statistical modeling approaches to minimize possible errors in the forecasts. This is also true for other areas of public health and biomedicine. The new FDA forecasting approaches $[23,25]$ are a natural extension of methods developed for mortality and fertility forecasting that have evolved over the last two decades in demography [25,133,134]. The methodology has therefore been used in a number of demographic applications and there have been various extensions and modifications proposed [25,134]. Somewhat surprisingly, the use of FDA forecasting in public health and biomedical applications has been limited to date.

\section{Conclusion}

In summary, this paper describes FDA and its important features as applied to time series data from various fields. Functional data analysis provides a relatively novel modeling and prediction approach, with the potential for many significant applications across a range of public health and biomedical applications. Importantly, not all FDA features always need to be used in a single study and the selection of specific analysis features will depend on the underlying behavior of the data, the nature of study and the specific research questions being posed. Consideration should be given to wider application of FDA and its important modeling features so that more accurate estimates for public health and biomedical applications can be generated. 


\section{Abbreviations}

FDA: Functional data analysis; FPCA: Functional principal component analysis; FLM: Functional linear modeling; LDA: Linear discriminant analysis; KNN: Knearest neighbours; SVM: Support vector machine; MBC: Model based clustering; QDA: Quadratic discriminant analysis; EDO: Estimated differential operators; FRM: Functional linear regression model; FANOVA: Functional ANOVA; FFT: Functional F-test; FLRM: Functional logistic regression model; FMANOVA: Functional multivariate analysis of variance.

\section{Competing interests}

The authors have no conflicts of interest that are directly relevant to the content of this review.

\section{Authors' contributions}

As first author, SU conceived and designed the study reported in this paper. He took the lead role in drafting the manuscript and reviewed all relevant articles and analysed their content. The second author, CF, provided expertise in the conduct of systematic reviews and also contributed to the writing and editing of the paper. She reviewed the article and revised it critically for important intellectual content. Both authors read and approved the final manuscript.

\section{Acknowledgements}

The study was funded (at least in part) through the Early Career Researcher development funding program at the University of Ballarat. Professor Caroline Finch was supported by a National Health and Medical Research Council (NHMRC) Principal Research Fellowship (ID: 565900). Peter Richardson and Dr Saad Saleem assisted with the original literature searches and retrieval of published articles for the review. Eileen Clark proofread and copy edited the manuscript.

\section{Author details}

${ }^{1}$ Flinders Centre for Epidemiology and Biostatistics, School of Medicine, Faculty of Health Sciences, Flinders University, Adelaide, SA 5001, Australia. ${ }^{2}$ Centre for Healthy and Safe Sports (CHASS), University of Ballarat, SMB Campus, Ballarat, VIC 3353, Australia.

\section{Received: 28 June 2012 Accepted: 4 March 2013}

\section{Published: 19 March 2013}

\section{References}

1. Green PJ, Silverman BW: Nonparametric regression and generalized linear models: A roughness penalty approach. London: Chapman and Hall; 1994.

2. Ramsay JO: When the data are functions? Psychometrika 1982, 47:379-396.

3. Ramsay JO: Monotone regression splines in action. Statist Sci 1988, 3:425-441.

4. Ramsay JO, Dalzell CJ: Some tools for functional data analysis. J R Stat Soc Series B Stat Methodol 1991, 53:539-572.

5. Müller HG: Functional data analysis. StatProb: The Encyclopedia Sponsored by Statistics and Probability Societies; 2011.

6. Ferraty F, Mas A, Vieu P: Advances in nonparametric regression for functional variables. Aust N Z J Stat 2007, 49:1-20.

7. Mas A, Pumo B: Functional linear regression with derivatives. J Nonparametr Stat 2009, 21:19-40.

8. Levitin DJ, Nuzzo RL, Vines BW, Ramsay JO: Introduction to functional data analysis. Can Psychol 2007, 48:135-155.

9. Ramsay JO, Silverman BW: Functional data analysis. 2nd edition. New York: Springer; 2005

10. Ramsay JO, Silverman BW: Applied functional data analysis. New York: Springer; 2002

11. Locantore N, Marron JS, Simpson DG, Tripoli N, Zhang JT, Kohen KL: Robust principal component analysis for functional data. TEST 1999, 8:1-73.

12. Yushkevich P, Pizer SM, Joshi S, Maron JS: Intuitive, localized analysis of shape variability, Proceedings of the Inf Process Med Imaging. 2001, 2082/2001:402-408.

13. Besse $\mathrm{PC}$, Cardot $\mathrm{H}$ : Autoregressive forecasting of some functional climate variations. Scand Stat Theory Appl 2000, 27:673-687.

14. Ramsay JO: Functional components of variation in handwriting. J Am Stat Assoc 2000, 95:9-15.

15. Abraham C, Cornillon PA, MatznerLober E, Molinari N: Unsupervised curve clustering using B-splines. Scand Stat Theory Appl 2003, 30:581-595.
16. Besse $P C$, Cardot $H$, Faivre R, Goulard M: Statistical modelling of functional data. Appl Stoch Model Bus Ind 2005, 21:165-173.

17. Pfeiffer RM, Bura E, Smith A, Rutter JL: Two approaches to mutation detection based on functional data. Stat Med 2002, 21:3447-3464.

18. Ratcliffe $S J$, Heller GZ, Leader LR: Functional data analysis with application to periodically stimulated foetal heart rate data. II: functional logistic regression. Stat Med 2002, 21:1115-1127.

19. Ratcliffe $S J$, Leader $L R$, Heller GZ: Functional data analysis with application to periodically stimulated foetal heart rate data. I: functional regression. Stat Med 2002, 21:1103-1114.

20. Rossi N, Wang X, Ramsay JO: Nonparametric item response function estimates with the EM algorithm. J Educ Behav Stat 2002, 27:291-317.

21. Kargin V, Onatski A: Curve forecasting by functional autoregression. J Multivar Anal 2008, 99:2508-2526.

22. Reiss PT, Ogden RT: Functional principal component regression and functional partial least squares. J Am Stat Assoc 2007, 102:984-996.

23. Ullah S, Finch CF: Functional data modelling approach for analysing and predicting trends in incidence rates-An application to falls injury. Osteoporos Int 2010, 21:2125-2134.

24. Erbas B, Hyndman RJ, Gertig DM: Forecasting age-specific breast cancer mortality using functional data models. Stat Med 2007, 26:458-470.

25. Hyndman RJ, Ullah MS: Robust forecasting of mortality and fertility rates: a functional data approach. Comput Stat Data Anal 2007, 51:4942-4956.

26. Rice JA: Functional and longitudinal data analysis: perspectives on smoothing. Statist Sci 2004, 14:631-647.

27. Davidian $M$, Lin X, Wang JL: Introduction: emerging issues in longitudinal and functional data analysis. Statist Sci 2004, 14:613-614.

28. Ullah S: Demographic forecasting using functional data analysis. Monash University: PhD Thesis; 2007.

29. Moher D, Liberati A, Tetzlaff J, Altman DG, The PRISMA Group: Preferred reporting items for systematic reviews and meta-analyses: The PRISMA statement. PLoS Med 2009, 6:e1000097.

30. Rasmussen IJ, Antonsen IK, Berntsen EM, XU J, Lagopoulos J, Haberg AK: Brain activation measured using functional magnetic resonance imaging during the Tower of London task. Acta Neuropsychiatr 2006, 18:216-225.

31. Buchanan AS, Docherty CL, Schrader J: Functional performance testing in participants with functional ankle instability and in a healthy control group. J Athl Train 2008, 43:342-346.

32. Swanik CB, Covassin T, Stearne DJ, Schatz P: The relationship between neurocognitive function and noncontact anterior cruciate ligament injuries. Am J Sports Med 2007, 35:943-948.

33. Gabrys R, Kokoszka P: Portmanteau test of independence for functional observations. J Am Stat Assoc 2007, 102:1338-1348.

34. Manteiga WG, Vieu P: Statistics for functional data. Comput Stat Data Anal 2007, 51:4788-4792.

35. Cardot H, Ferraty F, Mas A, Sarda P: Testing hypotheses in the functional linear model. Scand Stat Theory Appl 2003, 30:241-255.

36. Dura JV, Belda JM, Poveda R, Page A, Laparra J, Das J, Prat J, Garcia AC Comparison of functional regression and non-functional regression approaches to the study of the walking velocity effect in force platform measures. J Appl Biomech 2010, 26:234-239.

37. Crane EA, Cassidy RB, Rothman ED, Gerstner GE: Effect of registration on cyclical kinematic data. J Biomech 2010, 43:2444-2447.

38. Zhu HT, Styner M, Tang NS, Liu ZX, Lin WL, Gilmore JH: FRATS: Functional regression analysis of DTI tract statistics. IEEE Trans Med Imaging 2010, 29:1039-1049.

39. Wu P, Müller H: Functional embedding for the classification of gene expression profiles. Bioinformatics 2010, 26:509-517.

40. Kim SB, Rattakorn P, Peng YB: An effective clustering procedure of neuronal response profiles in graded thermal stimulation. Expert Syst App/ 2010, 37:5818-5826.

41. Hyndman RJ, Shang HL: Rainbow plots, bagplots, and boxplots for functional Data. J Comput Graph Stat 2010, 19:29-45.

42. Torres JM, Garcia Nieto PJ, Alejano L, Reyes AN: Detection of outliers in gas emissions from urban areas using functional data analysis. $J$ Hazard Mater 2010, 186:144-149.

43. Maslova I, Kokoszka P, Sojka J, Zhu L: Statistical significance testing for the association of magnetometer records at high-, mid- and low latitudes during substorm days. Planet Space Sci 2010, 58:437-445.

44. Hermanussen M: Auxology: An update. Horm Res Paediatr 2010, 74:153-164. 
45. Erbas B, Akram M, Gertig DM, English D, Hopper JL, Kavanagh AM, Hyndman RJ: Using functional data analysis models to estimate future time trends in age-specific breast cancer mortality for the United States and England-Wales. J Epidemiol 2010, 20:159-165.

46. Ogden RT, Greene E: Wavelet modeling of functional random effects with application to human vision data. J Stat Plan Inference 2010, 140:3797-3808.

47. Muller HG, Wu S, Diamantidis AD, Papadopoulos NT, Carey JR: Reproduction is adapted to survival characteristics across geographically isolated medfly populations. Proc Bio/ Sci 2009, 276:4409-4416.

48. Roislien J, Skare O, Gustavsen M, Broch NL, Rennie L, Opheim A: Simultaneous estimation of effects of gender, age and walking speed on kinematic gait data. Gait Posture 2009, 30:441-445.

49. Gouttard S, Prastawa M, Bullitt E, Lin W, Gerig G: Constrained data decomposition and regression for analyzing healthy aging from fiber tract diffusion properties. Med Image Comput Comput Assist Interv 2009, 12:321-328.

50. Illian JB, Prosser Jl, Baker KL, Rangel-Castro JL: Functional principal component data analysis: a new method for analysing microbial community fingerprints. J Microbiol Methods 2009, 79:89-95.

51. Parker BJ, Wen J: Predicting microRNA targets in time-series microarray experiments via functional data analysis. BMC Bioinforma 2009, 10:S32.

52. Goodlett CB, Fletcher PT, Gilmore GH, Gerig G: Group statistics of DTI fiber bundles using spatial functions of tensor measures. Med Image Comput Comput Assist Interv 2008, 11:1068-1075.

53. Jiang CR, Aston JA, Wang JL: Smoothing dynamic positron emission tomography time courses using functional principal components. Neurolmage 2009, 47:184-193.

54. Lee KL, Meyer RJ, Bradlow ET: Analyzing risk response dynamics on the web: the case of Hurricane Katrina. Risk Anal 2009, 29:1779-1792.

55. Oa D, Harrison AJ, Coffey N, Hayes K: Functional data analysis of running kinematics in chronic Achilles tendon injury. Med Sci Sports Exerc 2008 40:1323-1335

56. Baladandayuthapani V, Mallick BK, Young HM, Lupton JR, Turner ND, Carroll $\mathrm{RJ}$ : Bayesian hierarchical spatially correlated functional data analysis with application to colon carcinogenesis. Biometrics 2008, 64:64-73.

57. Muller $H$, Chiou J, Leng $X$ : Inferring gene expression dynamics via functional regression analysis. BMC Bioinforma 2008, 9:60.

58. Park C, Koo J, Kim S, Sohn I, Lee JW: Classification of gene functions using support vector machine for time-course gene expression data. Comput Stat Data Anal 2008, 52:2578-2587.

59. Song JJ, Deng W, Lee H, Kwon D: Optimal classification for time-course gene expression data using functional data analysis. Comp Bio Chem 2008, 32(6):426-432

60. Hyndman $\mathrm{R}$, Booth $\mathrm{H}$ : Stochastic population forecasts using functional data models for mortality, fertility and migration. Int J Forecast 2008, 24:323-342.

61. Ikeda T, Dowd M, Martin JL: Application of functional data analysis to investigate seasonal progression with interannual variability in plankton abundance in the bay of Fundy, Canada. Estuar Coast Shelf Sci 2008, 78:445-455.

62. Guo W: Functional data analysis in longitudinal settings using smoothing splines. Stat Methods Med Res 2004, 13:49-62.

63. Laukaitis A: Functional data analysis for cash flow and transactions intensity continuous-time prediction using Hilbert-valued autoregressive processes. Eur J Oper Res 2008, 185:1607-1614.

64. Bapna R, Jank W, Shmueli G: Price formation and its dynamics in online auctions. Decis Support Syst 2008, 44:641-656.

65. Koenig LL, Lucero JC, Perlman E: Speech production variability in fricatives of children and adults: results of functional data analysis. J Acoust Soc Am 2008, 124:3158-3170.

66. Harezlak J, Wu MC, Wang M, Schwartzman A, Christiani DC, Lin X: Biomarker discovery for arsenic exposure using functional data. Analysis and feature learning of mass spectrometry proteomic data. J Proteome Res 2008, 7:217-224.

67. Chapados C, Levitin DJ: Cross-modal interactions in the experience of musical performances: physiological correlates. Cognition 2008, 108:639-651.

68. Song JJ, Lee H, Morris JS, Kang S: Clustering of time-course gene expression data using functional data analysis. Comp Bio Chem 2007, $31: 265-274$.
69. Vakorin VA, Borowsky R, Sarty GE: Characterizing the functional MR response using Tikhonov regularization. Stat Med 2007, 26:3830-3844.

70. Dabo-niang S, Vieu P: On the using of modal curves for radar waveforms classification. Comput Statist Data Anal 2007, 51:48-78.

71. Gao H: Day of week effects on diurnal ozone/NOx cycles and transportation emissions in Southern California. Transp Res Part D Transp Envr 2007, 12:292-305.

72. Meiring W: Oscillations and time trends in stratospheric ozone levels. J Am Stat Assoc 2007, 102:788-802.

73. Meyer PM, Zeger SL, Harlow SD, Sowers M, Crawford S, Luborsky JL, Janssen I, McConnell DS, Randolph JF, Weiss G: Characterizing daily urinary hormone profiles for women at midlife using functional data analysis. Am J Epidemiol 2007, 165:936-945.

74. West RM, Harris K, Gilthorpe MS, Tolman C, Will EJ: Functional data analysis applied to a randomized controlled clinical trial in hemodialysis patients describes the variability of patient responses in the control of renal anemia. J Am Soc Nephrol 2007, 18:2371-2376.

75. Harrison A, Ryan W, Hayes K: Functional data analysis of joint coordination in the development of vertical jump performance. Sports Biomech 2007, 6:199-214

76. Leng X, Muller $\mathrm{H}$ : Classification using functional data analysis for temporal gene expression data. Bioinformatics 2006, 22:68-76.

77. Zhang Y, Muller HG, Carey JR, Papadopoulos NT: Behavioral trajectories as predictors in event history analysis: male calling behavior forecasts medfly longevity. Mech Ageing Dev 2006, 127:680-686.

78. Duhamel A, Devos P, Bourriez JL, Preda C, Defebvre L, Beuscart R: Functional data analysis for gait curves study in Parkinson's disease. Stud Health Technol Inform 2006, 124:569-574.

79. Ryan W, Harrison A, Hayes K: Functional data analysis of knee joint kinematics in the vertical jump. Sports Biomech 2006, 5:121-138.

80. Page A, Ayala G, Leon MT, Peydro MF, Prat JM: Normalizing temporal patterns to analyze sit-to-stand movements by using registration of functional data. J Biomech 2006, 39:2526-2534.

81. Henderson B: Exploring between site differences in water quality trends: a functional data analysis approach. Environmetrics 2006, 17:65-80.

82. Stewart K, Darcy D, Daniel S: Opportunities and challenges applying functional data analysis to the study of open source software evolution. Stat Sci 2006, 21:167-178.

83. Lee S, Byrd D, Krivokapicl J: Functional data analysis of prosodic effects on articulatory timing. J Acoust SoC Am 2006, 119:1666-1671.

84. Newell J, McMillan K, Grant S, McCabe G: Using functional data analysis to summarise and interpret lactate curves. Comput Biol Med 2006, 36:262-275.

85. Vines BW, KrumhansI CL, Wanderley MM, Levitin DJ: Cross-modal interactions in the perception of musical performance. Cognition 2006 101:80-113.

86. Bensmail H, Aruna B, Semmes OJ, Haoudi A: Functional clustering algorithm for high-dimensional proteomics data. J Biomed Biotechno 2005, 2:80-86.

87. Ormoneit D, Black MJ, Hastie T, Sidenbladh H: Representing cyclic human motion using functional analysis. Image Vision Comput 2005, 23:1264-1276.

88. Viviani R, Gron G, Spitzer M: Functional principal component analysis of fMRI data. Hum Brain Mapp 2005, 24:109-129.

89. Long CJ, Brown EN, Triantafyllou C, Aharon I, Wald LL, Solo V: Nonstationary noise estimation in functional MRI. Neurolmage 2005, 28:890-903.

90. Manté C, Durbec JP, Dauvin JC: A functional data-analytic approach to the classification of species according to their spatial dispersion. Application to a marine macrobenthic community from the Bay of Morlaix (western English Channel). J App/ Stat 2005, 32:831-840.

91. Rupp A: Quantifying subpopulation differences for a lack of invariance using complex examinee profiles: an exploratory multigroup approach using functional data analysis. Edu Res Eval 2005, 11:71-97.

92. Laukaitis A: Functional data analysis for clients segmentation tasks. Eur J Oper Res 2005, 163:210-216.

93. Lucero JC: Comparison of measures of variability of speech movement trajectories using synthetic records. J Speech Lang Hear Res 2005, 48:336-344.

94. Vines BW, Nuzzo RL, Levitin DJ: Analysing temporal dynamics in music. Music Percept 2005, 23:137-152. 
95. Hutchinson RA, McLellan PJ, Ramsay JO, Sulieman H, Bacon DW: Investigating the impact of operating parameters on molecular weight distributions using functional regression. Macromol Symp 2004, 206:495-508.

96. Stier AW, Stein HJ, Schwaiger M, Heidecke CD: Modeling of esophagea bolus flow by functional data analysis of scintigrams. Dis Esophagus 2004, 17:51-57.

97. Liggett WS, Barker PE, Semmes OJ, Cazares LH: Measurement reproducibility in the early stages of biomarker development. Dis Markers 2004, 20:295-307.

98. Buckner RL, Head D, Parker J, Fotenos AF, Marcus D, Morris JC, Snyder AZ: A unified approach for morphometric and functional data analysis in young, old, and demented adults using automated atlas-based head size normalization: reliability and validation against manual measurement of total intracranial volume. Neurolmage 2004, 23:724-738.

99. McAdams S: Influences of large-scale form on continuous ratings in response to a contemporary piece in a live concert setting. Music Percept 2004, 22:297-350.

100. Spitzner DJ, Marron JS, Essick GK: Mixed-model functional ANOVA for studying human tactile perception. J Am Stat Assoc 2003, 98:263-272.

101. Yao F, Muller HG, Clifford AJ, Dueker SR, Follett J, Lin Y, Buchholz BA, Vogel JS: Shrinkage estimation for functional principal component scores with application to the population kinetics of plasma folate. Biometrics 2003, 59:676-685.

102. Ogden RT, Miller CE, Takezawa K, Ninomiya S: Functional regression in crop lodging assessment with digital images. J Agric Biol Environ Stat 2002, 7:389-402

103. Clarysse P, Han M, Croisille P, Magnin IE: Exploratory analysis of the spatiotemporal deformation of the myocardium during systole from tagged MRI. IEEE Trans Biomed Eng 2002, 49:1328-1339.

104. Ramsay JO, Ramsey BJ: Functional data analysis of the dynamics of the monthly index of nondurable goods production. J Econ 2002, 107:327-344

105. Hall P, Poskitt D, Presnell B: A functional data-analytic approach to signal discrimination. Technometrics 2001, 43:1-24.

106. Lucero JC, Koenig LL: Time normalization of voice signals using functional data analysis. J Acoust Soc Am 2000, 108:1408-1420.

107. Besse PC, Cardot H, Stephenson DB: Autoregressive forecasting of some functional climatic variations. Scand Stat Theory App/ 2000, 27:673-687.

108. Lucero JC: Computation of the harmonics-to-noise ratio of a voice signal using a functional data analysis algorithm. J Sound Vibrat 1999, 222:512-520.

109. Bjornstad O, Chr SN, Saitoh T, Lingjaerde OC: Mapping the regional transition to cyclicity in clethrionomys rufocanus: spectral densities and functional data analysis. Res Pop Ecol 1998, 40:77-84.

110. Ramsay JO, Munhall KG, Gracco VL, Ostry DJ: Functional data analyses of lip motion. J Acoust Soc Am 1996, 99:3718-3727.

111. Ramsay JO, Wang X: A functional data analysis of the pinch force of human fingers. App Stat 1995, 44:17-30.

112. Grambsch PM, Randall BL, Bostick RM, Potter JD, Louis TA: Modeling the labeling index distribution: An application of functional data analysis. J Am Stat Assoc 1995, 90:813-821.

113. Eubank RL: Nonparametric regression and spline smoothing. New York: Marcel Dekker; 1999.

114. Marx BD, Eilers PHC: Direct generalized additive modeling with penalized likelihood. Comput Stat Data Anal 1998, 28:193-209.

115. Wood SN: Modelling and smoothing parameter estimation with multiple quadratic penalties. J R Stat Soc Series B Stat Methodol 2000, 62:413-428.

116. Gao H, Niemeier D: Using functional data analysis of diurnal ozone and NOx cycles to inform transportation emissions control. Transp Res Part D Transp Envr 2008, 13:221-238.

117. Ruppert D, Wand MP, Carroll RJ: Semiparametric regression. Cambridge: New York; 2003.

118. Simonoff JS: Smoothing methods in statistics. New York: Springer; 1996.

119. Croux C, RuizGazen A: High breakdown estimators for principal components: The project-pursuit approach revisited. J Multivar Anal 2005, 95:206-226.

120. Ferraty F, Vieu P: Nonparametric functional data analysis. New York: Springer; 2006.

121. Kneip A, Utikal $\mathrm{KJ}$ : Inference for density families using functional principal component analysis. J Am Stat Assoc 2001, 94:519-533.

122. James GM, Hastie TJ, Sugar CA: Principal component models for sparse functional data. Biometrika 2001, 87:587-602.
123. Wang $H$, Neill J, Miller F: Nonparametric clustering of functional data. Stat Interface 2008, 1:47-62.

124. Dudoit S, Fridlyand J, Speed TP: Comparison of discrimination methods for the classification of tumors using gene expression data. J Am Stat Assoc 2002, 97:77-87.

125. Lee JW, Lee JB, Park M, Song SH: An extensive comparison of recent classification tools applied to microarray data. Comput Statist Data Anal 2005, 48:869-885.

126. Denoeux T: A K-nearest neighbor classification rule based on DempsterShafer theory. IEEE Trans Syst Man Cybernet 1995, 25:804-813.

127. Keller JM, Gray MR, Givens JA: A fuzzy k-nearest neighbours algorithm. IEEE Trans. Syst. ManCybern 1985, 15:580-585.

128. Cortes C, Vapnik V: Support-vector networks. Mach Learn 1995, 20:273-297.

129. Fraley C, Raftery AE: Model-based clustering, discriminant analysis, and density estimation. J Am Stat Assoc 2002, 97:611-631.

130. Hyndman RJ, Koehler AB, Snyder RD, Grose S: A state space framework for automatic forecasting using exponential smoothing methods. Int $J$ Forecast 2002, 18:439-454.

131. Santen G, van Zwet E, Danhof M, Pasqua OD: Heterogeneity in patient response in depression: The relevance of functional data analysis. Universiteit Leiden, Netherland: PhD Thesis; 2008.

132. Finch CF, Hayen A: Governmental health agencies need to assume leadership in injury prevention. Inj Prev 2006, 12:2-3.

133. Lee RD, Carter LR: Modeling and forecasting U.S. mortality. J Am Stat Assoc 1992, 87:659-675.

134. Lee RD, Miller T: Evaluating the performance of the Lee-Carter method for forecasting mortality. Demography 2001, 38:537-549.

doi:10.1186/1471-2288-13-43

Cite this article as: Ullah and Finch: Applications of functional data analysis: A systematic review. BMC Medical Research Methodology 2013 $13: 43$.

\section{Submit your next manuscript to BioMed Central and take full advantage of:}

- Convenient online submission

- Thorough peer review

- No space constraints or color figure charges

- Immediate publication on acceptance

- Inclusion in PubMed, CAS, Scopus and Google Scholar

- Research which is freely available for redistribution
C Biomed Central 